\title{
ADULT-ONSET STILL'S DISEASE OR MULTISYSTEMIC INFLAMMATORY SYNDROME: A DIAGNOSTIC CHALLENGE AFTER PANDEMIC - CASE REPORT
}

Daniela Esteves Temporim ${ }^{1, \star}$, Matheus Zanata Brufatto1, Sean Hideo Shirata Lanças ${ }^{1}$, Andrea de Almeida Peduti Batista ${ }^{1}$, Laura Maria Silva de Siqueira ${ }^{1}$, Douglas Squizatto Leite ${ }^{1}$, Henrique Pereira Sampaio ${ }^{1}$, Luiz Eduardo Valente ${ }^{1}$, João Flávio Gomes Faria $^{1}$, Sula Glaucia Lage Drumond Pacheco ${ }^{1}$

1.Universidade Estadual Paulista “Júlio de Mesquita Filho", Botucatu (SP), Brazil.

*Corresponding author: d.temporim1993@gmail.com

\section{BACKGROUND}

Adult-onset Still's disease (AoSD) is a rare systemic inflammatory condition characterized by arthritis, fever, skin rash and elevated levels of ferritin. It is a complex disorder, marked by unregulated immune system, where particular aspects of autoimmune diseases, such as the production of autoantibodies, are absent. The SARS-CoV-2 pandemic brought a new condition, well characterized in the pediatric population, called multisystemic inflammatory syndrome in children (MIS-C), whose presentation occurs late in the course of coronavirus infection, with fever, mucocutaneous findings, myocardial dysfunction, shock and lymph node enlargement. Increased inflammatory markers are common.

\section{CASE REPORT}

Female, 17 years old, black, previously healthy, had asymptomatic coronavirus infection. After 5 weeks, she started prostration, myalgia, arthralgia, odynophagia, daily fever, with two peaks, and maculopapular rash. On physical examination on admission, she was in poor general condition, hypotensive $(70 \times 40 \mathrm{mmHg})$, tachycardia $(145 \mathrm{bpm})$, with lymph node enlargement in the cervical chain and maculopapular rash on the trunk and limbs, which spared the palms of the hands and feet. There were right elbow and ankle arthritis. Laboratory tests showed leukocytosis with a predominance of neutrophils (15.2 leukocytes $/ \mathrm{mm}^{3}$ with 12,940 neutrophils $/ \mathrm{mm}^{3}$ ), anemia, thrombocytosis, ESR $74 \mathrm{~mm} / \mathrm{h}$, C-reactive protein $21.7 \mathrm{mg} / \mathrm{dL}$, fibrinogen $410 \mathrm{mg} / \mathrm{dL}$, ferritin $>1650 \mathrm{ng} / \mathrm{mL}$, total bilirubin $3.2 \mathrm{mg} / \mathrm{dL}$, at the expense of direct bilirubin $2.7 \mathrm{mg} / \mathrm{dL}$. Rheumatoid factor and ANA negative. Echocardiogram with left ventricular systolic dysfunction (ejection fraction $50 \%$, Simpson). Hypothesis of AoSD with differential MIS-C was performed. Methylprednisolone pulse was started, $1 \mathrm{~g} /$ day, for 3 days, with complete improvement of complaints and normalization of laboratory and imaging tests.

\section{CONCLUSION}

This case portrays the possibility of an intersection between the diagnostic criteria of AoSD and MIS-C, since both pathologies are characterized by intense inflammatory activity, with the possibility of damage to target organs. Once active infections or other underlying diseases are ruled out, the treatment for both is immunosuppression with high doses of glucocorticoids and immunoglobulin may be used if the patient does not respond.

\section{KEYWORDS}

Still, MIS-C, Sars-CoV-2. 